\title{
MICRATOPUS CASEY IN THE UNITED STATES (COLEOPTERA: CARABIDAE: BEMBIDIINAE)
}

\author{
By Thomas C. Barr, Jr. \\ University of Kentucky, Lexington
}

The late René Jeannel (e.g., I946, p. 33I) divided the bembidiine carabids, which he regarded as a subfamily Bembidiitae, into four tribes: Anillini, Limnastini, Tachyini, and Bembidiini. He included Micratopus Casey (I9I4, p. 42) and Limnastis Motschulsky in the Limnastini, although the former genus had previously formed the type of Casey's tribe Micratopini. Ball (I960) retained Micratopini as a tribe of the Carabidae, but his "Bembidiini" is equivalent to the "Anillini", "Tachyini", and "Bembidiini" of Jeannel. Ball's classificatory scheme thus implies that Limnastis and Micratopus are phylogenetically so remote that they merit a hierarchical status equivalent to that of all other bembidiines.

Prior to his death Dr. Jeannel (in litt.) indicated to me that he had used the name Limnastini rather than Casey's older name Micratopini because he had not examined sufficient material of Micratopus and preferred the name of the tribe to be based on a well-known genus. After comparison of several species of Micratopus with several Old World species of Limnastis sent to me by Jeannel I see no reason not to apply the law of priority and accept 'Casey's tribal name Micratopini, with Limnastini a synonym. However, Micratopini would become at best a subtribe in Bembidiini s. lat. in the classification of Ball (1960).

Parenthetically it should be noted that Horologion speokoites Valentine (1932), an eyeless carabid known only from the unique holotype male taken in a West Virginia cave, has many features in common with the more primitive bembidiines (cf. Barr, I969, p. 87). In my opinion it should be included within the subfamily Bembidiinae (or tribe Bembidiini s. lat.) close to and perhaps hierarchically coequal with the Anillini, rather than be relegated to the Psydrini, as was suggested by Valentine (1932) and actually done by Ball (ig6o).

\section{Micratopus Casey}

Casey, 1914, p. 42. Type species, M. fusciceps Casey, by original designation.

There appears to be a single species of Micratopus in the southeastern United States, $M$. aenescens (LeConte). The species of the 
genus are distributed from the Gulf Coastal Plain and Interior Low Plateaus of the United States through Central America and the West Indies at least as far south as Panama and Trinidad. Collections are erratic; the largest series have come from berlesates of forest floor litter in swampy areas, or from black light traps near marshes and ponds. In Florida Mr. Harrison R. Steeves, Jr., obtained numerous $M$. aenescens from several localities by extracting them from leaf litter at the margins of lakes and swamps. In Putnam County, Tennessee, I found that I could regularly collect a few specimens from the rotting interior of an old chestnut log which lay on a small island in a wooded swamp. I took a single specimen by sifting debris in the damp, cool, sinkhole at the entrance to Bull Cave, Great Smoky Mountains National Park, Blount County, Tennessee. Casey (I9I4) states that his type series of $\boldsymbol{M}$. fusciceps was taken by sifting leaf litter in a ravine near Vicksburg, Mississippi. The beetles are very active and crawl rapidly away when disturbed, but do not attempt flight. I have found them crawling out of the top of open Berlese funnels as often as falling through into the collecting dish. From all indications Micratopus spp. may be very abundant in favorable localities, but special techniques - litter processing or use of black light traps in swampy areas - seem indicated to obtain large series. These techniques have been seldom

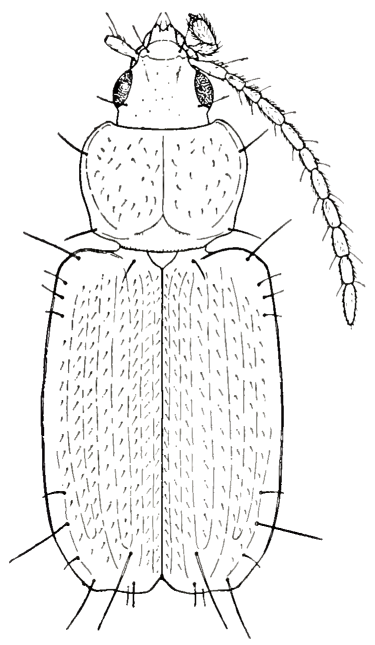

Fig. 1. Micratopus aenescens (LeConte), Putnam County, Tennessee. Length $2.4 \mathrm{~mm}$. 
employed by the average carabid collector, which probably explains the apparent rarity of species of this genus.

\section{Micratopus aenescens (LeConte)}

Figures $\mathrm{I}, 2$

Blemus aenescens LeConte, 1848, p. 473. Type locality, "Georgia", probably Habersham County. Type in Harvard Museum of Comparative Zoology. Tachys aenescens: Hayward, 1900, p. 197.

Micratopus aenescens: Casey, 1914, p. 43.

Micratopus fusciceps Casey, 1914, p. 43. Type locality, Vicksburg. Mississippi. Type in United States National Museum. NEW SYNonymy.

Length 2.I-2.5 mm. Dorsum of head dark chestnut; clypeus, labrum, antennae, pronotum and elytra brownish-piceous; maxillary and labial palps, femora, coxae, and underparts of tibiae and tarsi flavotestaceous. Microsculpture of pronotum and elytra a very fine, anastomosing meshwork which imparts an opalescent cast; microsculpture of head isodiametric, open; integument more or less pubescent, least so on dorsum of head.

Head with sides convergent, a little longer than wide, dorsum with minute punctures sparsely scattered and visible only at high magnification; labrum deeply emarginate, lateral lobes folded down over and partly obscuring mandibles, anterior margin bearing only four setae; mandibles short, thick, bifid at tip, without a seta in scrobe; mentum edentate, submentum with four (prebasilar) setae; maxillary and labial palps about as in Limnastis, penultimate segments inflated, heavily pubescent, last segments minute, hyaline, glabrous; clypeus with a seta at each side, clypeolabral suture arcuate, convex forward; frontal grooves shallow and very short, convergent; eyes large and freely convex; only one pair of supraorbital setae.

Pronotum about seven-tenths as long as wide, sides rounded and very feebly sinuate before the rounded, obtuse hind angles; base oblique behind hind angles, so that base is feebly "lobed"; marginal gutter rather broad, hind angles not carinate; disc sparsely pubescent.

Elytra broad, depressed, subparallel, humeri prominent and apexes broadly truncate, length almost I.5 times combined width; longitudinal striae moderately deep, distinct, interstriae each with a row of short pubescence; a single discal puncture on third stria near apex; umbilicate series with whips in punctures $\mathrm{I}, 6$, and 8 .

Antenna about six-tenths as long as body, segments II and III subequal and about six-tenths as long as segment IV; all segments more or less pubescent, but becoming more so from scape to segment 


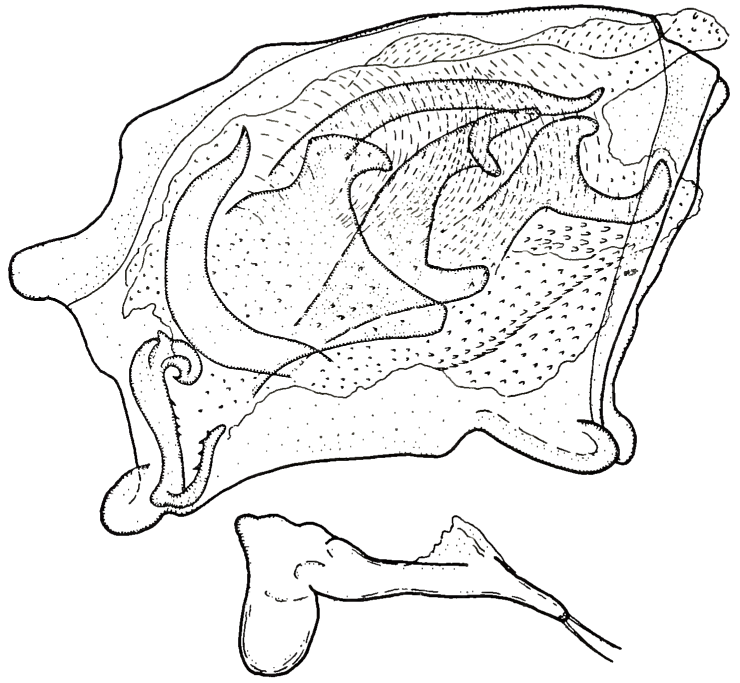

Fig. 2. Aedeagus of Micratopus aenescens (LeConte), left lateral view, composite sketch from four preparations. Paramere shown detached. Length $0.30 \mathrm{~mm}$., height $0.16 \mathrm{~mm}$.

IV. Male tarsi not differentiated from female; last abdominal sternite with only two marginal setae in both sexes. Protibia obliquely truncate near apex.

Aedeagus (Figure 2) highly modified, trapezoidal, short, thick, and laterally compressed, about $0.16 \times 0.30 \mathrm{~mm}$. long; right side with a loosely attached lamina projecting a short distance upward and forward and articulating with a single slender (left?) paramere bearing two seatae at its apex; basal orifice a simple slot with no evident lobes; aedeagus walls thin, hyaline, with a thin sclerotized strip antero-dorsally and another, vertical strip at apex on left side; internal sac with six rather complex sclerites: I) basoventral: scroll-shaped, bifurcated, with minute spines internally; (2) dorsal: a slender, horizontally oriented, arcuate spicule; 3 ) basal: a slender, vertically oriented, arcuate spicule; 4) first medial: broad, bilobed, with a dorsal hook and ventral projection; 5 ) second medial: slender, bilobed, dorsal lobe bifurcate; and 6) apical: a blade-like hook.

Measurements of a male from Galts Landing, Cherokee County, Georgia ( $T$. Barr, private collection): total length $2.44 \mathrm{~mm}$., head $0.48 \mathrm{~mm}$. long $\times 0.44 \mathrm{~mm}$. wide, pronotum $0.50 \mathrm{~mm}$. long $\times 0.68 \mathrm{~mm}$. wide, elytra $\mathrm{I} .46 \mathrm{~mm}$. long $\times$ I.OI mm. wide (combined), antenna $1.46 \mathrm{~mm}$. long, aedeagus $0.30 \mathrm{~mm}$. long. 
Geographic Distribution:- I have seen this species from the following localities; abbreviations are USNM: United States National Museum; MCZ: Museum of Comparative Zoology, Harvard University; and TCB: my private collection.

alabama: Selma (USNM). arkansas: Carlisle (MCZ); "Ark." (Hayward, MCZ). FLORIDA: Enterprise (USNM); Tampa (USNM); numerous specimens in Berlese samples from Alachua, Baker, Dade, Highlands, and Seminole counties (TCB). GEORgia: "Georgia", probably Habersham County (LeConte, MCZ); Galt's Landing, Cherokee County (TCB). Indiana: 5 miles west of Hardinsburg (USNM). Louisiana: Bay Sara (USNM) ; Houma (MCZ); Opelousas (Hayward, MCZ); Tallulah (USNM). MISSISSIPPI: Vicksburg (Casey, USNM). SOUTH carolina: "S.C." (MCZ). TEnNessee: Bugger Swamp, near Cookeville, Putnam County (TCB); Bull Cave, Blount County (TCB).

The range of $M$. aenescens is thus outlined as predominantly the Gulf Coastal Plain, with significant penetration northward into the Interior Low Plateaus (to Hardinsburg, Indiana). Leng (I920, p. 54) lists the species from "N.C.", and it must certainly occur in Kentucky and possibly in southeastern Virginia. The apparent absence of Micratopus from southeastern Texas is probably a collecting accident.

Discussion:- The species of Micratopus are differentiated with some difficulty, primarily because the range of variation within a species is difficult to determine with scattered material. Most of them, like $M$. aenescens, are probably rather widely distributed. The aedeagi resemble that of aenescens but are not easy to extract from dried specimens and are usually difficult or impossible to interpret unless several preparations are made. The accompanying figure of the aedeagus of $M$. aenescens (Fig. 2) was made with camera lucida but represents a composite of four aedeagi extracted from specimens at the same locality. I believe that the six minute sclerites of the internal sac, described in some detail for aenescens, have homologues in the Mexican and Central American species as well as those of the West Indies, and may prove to be of value in a diagnostic sense when the genus as a whole is investigated.

The complex aedeagal structure presumably represents an aberrant and peculiar specialization. As such, it is of little help in determining the position of Micratopus within a bembidiine classificatory scheme. The external resemblances to Limnastis, however, leave little doubt that the two genera are closely related. Common features include 
the deeply cleft labrum, the single pair of supraorbital punctures, the form of the maxillary and labial palps, the loosely aggregated umbilicate series of 9 punctures, the subtruncate elytral apexes, the absence of both the apical recurrent groove and a twisted epipleural fold, and the testaceous color. In view of the radically modified aedeagus of Micratopus, however, I prefer to retain both genera.

BALL, GEORge E.

\section{Literature Cited}

1960. Carabidae, pp. 55-181, in Arnett, Ross H., Jr.: The beetles of the United States. Washington: Catholic Univ. America Press. Barr, ThOMAS C., JR.

1969. Evolution of the Carabidae (Coleoptera) in the southern Appalachians, pp. 67-92, in Holt, Perry C., ed.: The distributional history of the biota of the southern Appalachians. Virginia Poly-

Casey, Thomas L. tech. Inst., Blacksburg, Res. Mon. 1, 295 pp.

1914. Memoirs on the Coleoptera, V. Lancaster, Pennsylvania.

HAYWARD, ROLAND

1900. A study of the species of Tachys of boreal America. Trans. American Entomol. Soc., 26 (1899): 191-238, pl. 6.

JEANNEL, RENÉ

1946. Coléoptères carabiques de la région malgache (première partie). Mus. Nat. Hist. Nat., Paris, 372 pp.

LE CONTE, JoHN L.

1848. A descriptive catalogue of the geodephagous Coleoptera inhabiting the United States east of the Rocky Mountains. Ann. Lyc. Nat.

Leng, Charles W. Hist. New York, 4: 173-233, 334-474 (pagination error).

1920. Catalogue of the Coleoptera of America, north of Mexico. Mount Vernon, New York: $470 \mathrm{pp}$.

VALENTINE, J. MANSON

1932. Horologion, a new genus of cave bettles (fam. Carabidae). Ann. Entomol. Soc. America, 25: pp. 1-8, 2 pls. 


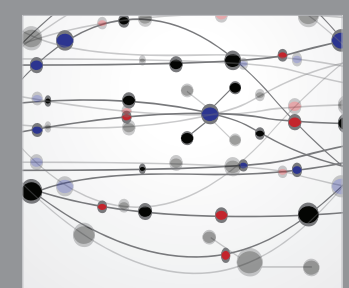

The Scientific World Journal
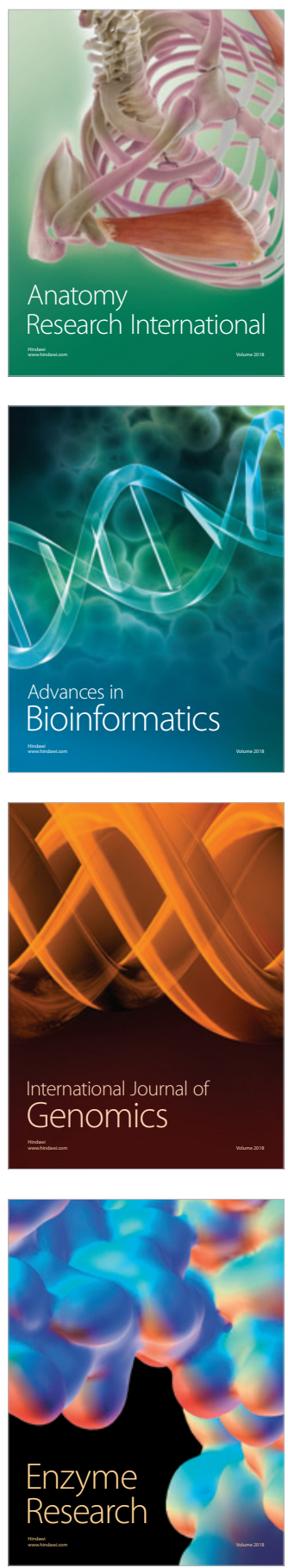
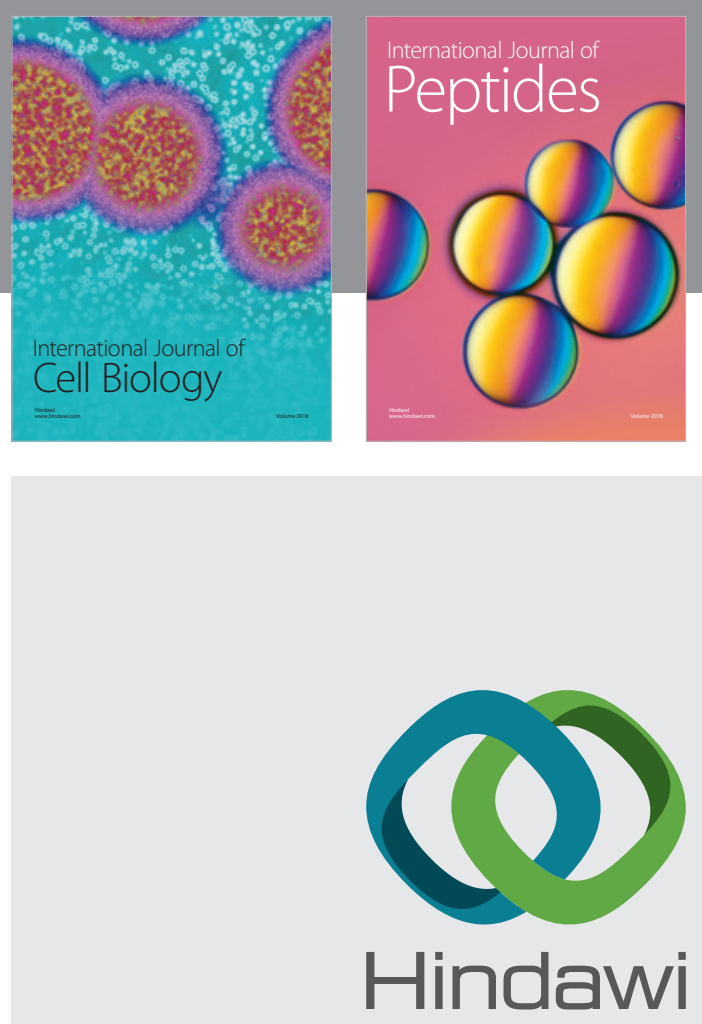

Submit your manuscripts at

www.hindawi.com
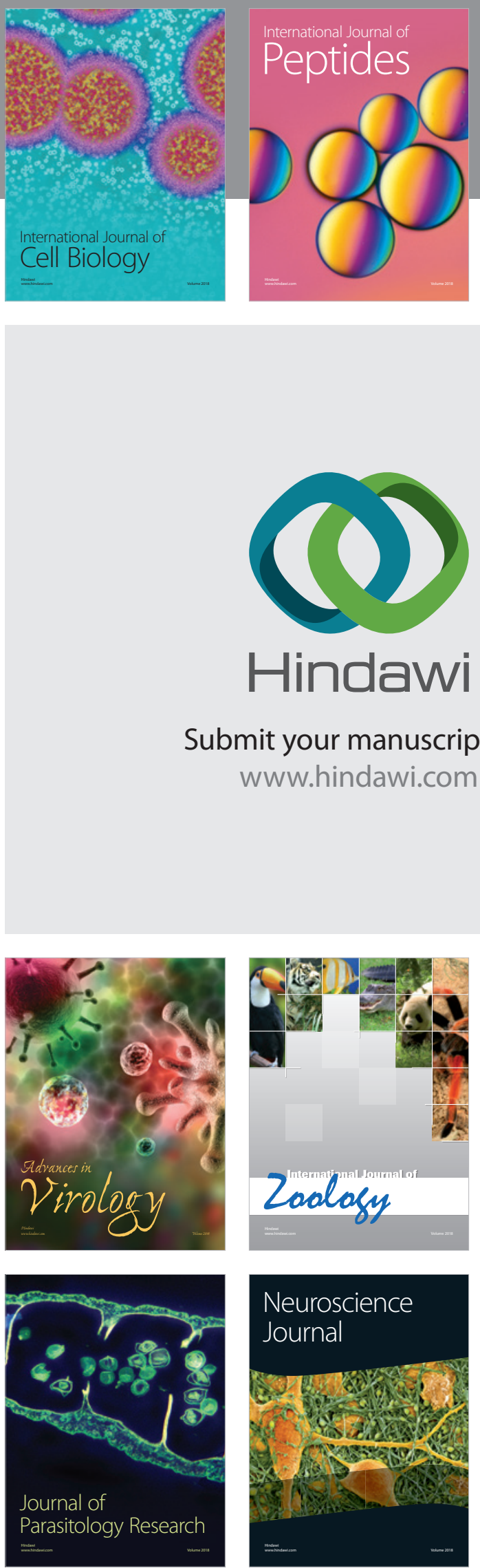
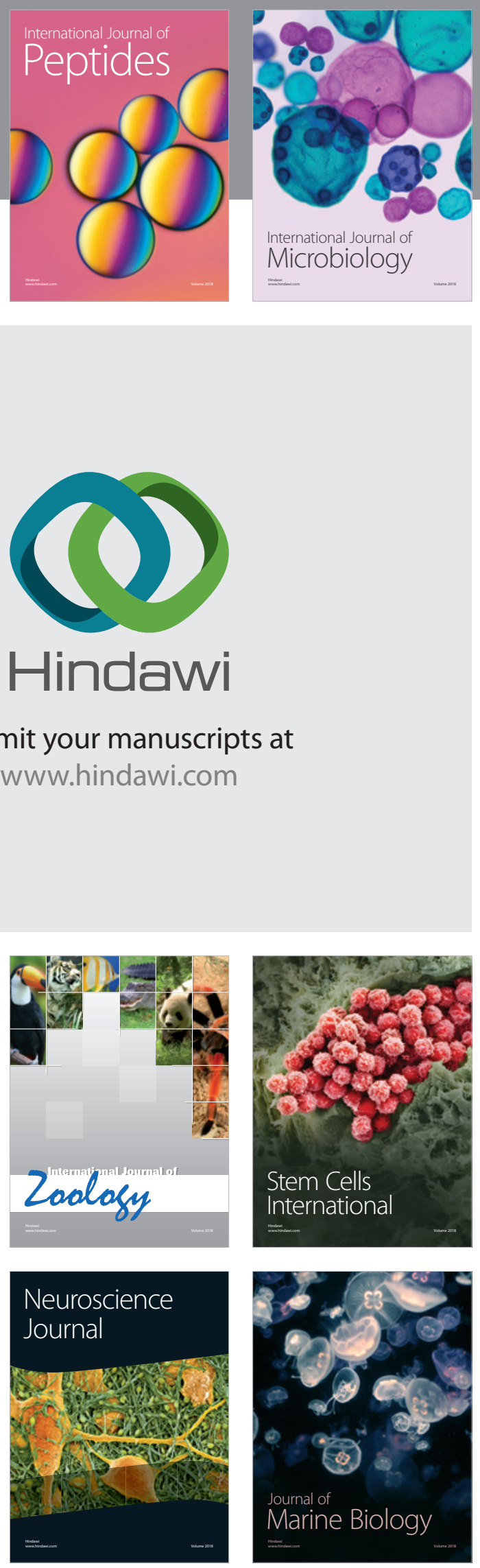
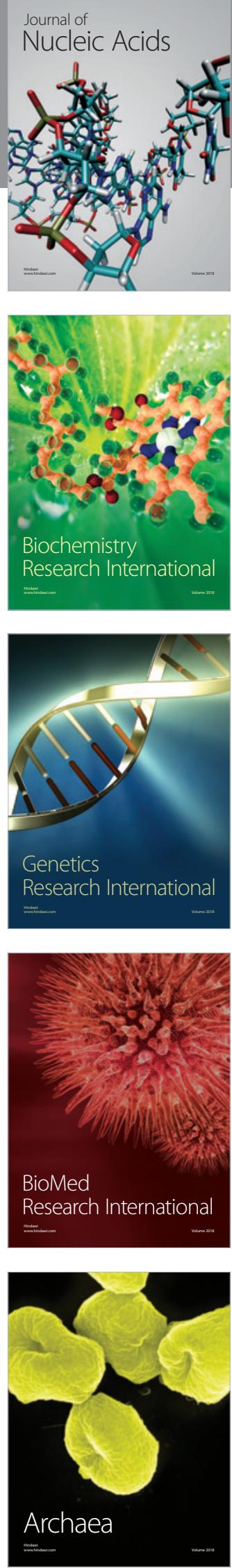